we include under the term geographical, i. e., wide areas depicted topographically on small scales within the rigid lines of a restricted sheet, these variations in quality of accuracy become far more pronounced and more important. No one but the compiler (who keeps the record) can possibly say what is the exact value of any one portion of the map, how far it is to be trusted in the business of conducting military affairs or the in the business of conducting military affairs or

A naive belief in the accuracy of a printed map com pilation has foundered many a high political programme, even when the geographical features which may form the basis for a treaty have already been correctly shown as they existed at the time the map wa made. The face of the earth changes and locally changes very fast.

No need to elaborate this propensity of our eart world to change its face or of its more primitive inhabitants to change their habitations and call them perpetually by new names. I only refer to it as a cautio to map cities.

I have said a word or two indicating that the gift of imagination must still have its place in map-making. This may sound almost immoral, although it is but a page from past records, and yet I have come to the conclusion that if the public is asked to exercise imagination in reading the map, the map-maker must meet the public half way. It is still, of course, in the domain of geographical mapping where the conformation of the round is partly well known, partly indifferently known, that imagination must here and there be calle upon to supplement actual knowledge. If the mapmaker were to confine hintself to absolutely what he knew to be true in the delineation of mountain and ralley, or of rough desert areas wherein no living creature moved, he would simply leave large white blanks in his map which might in themselves be most miseading.

It used to be the fashion to leave such blanks, but in my opinion it is better to introduce mountains or de erts where they are known to exist, to indicate all that can be seen from a distance than to make no sign at all. The part of the map which is conjectural should, of course, be carefully indicated; but there is doubtless a tendency on the part of enthusiastic explorers to consider much of these conjectures as certainty and to make no specific distinctions between what they know and what they think they know. In this way it often happens that succeeding explorers in the same region are apt to condemn the work of their predecessors from want of knowledge of the exact nature of the different parts of that work.

I may say just a word here about map criticism. It is a most common thing for even intelligent travelers passing over a country with a map in their hands to report that they found the map all wrong. Now, in the case of expeditions into partially known lands, it is only the expert who can say whether the criticism is a jus one or not. It most cases it is not, for the simple reason that ordinary travelers have no means of identifying their position and do not know exactly where they stand; while, as regards place names, although they may succeed in identifying the position. named, they are at the mercy of native guides and interpreters for their own information.

There is one matter about which experts disagree more or less, and it is one on which I think the public might well express an opinion. It is the fashion now to indicate successive planes of elevation by flat tint, and the ordinary application of color for that purpose is in shades of green for the lower elevations, rising into brown which deepens with the altitude. So well known is this system that I think it may be considered to have established a fair claim to permanence, so far as British maps are concerned. For my own part, I can imagine nothing better for ordinary touring maps. But difficulty arises when the altitudes are great, rising to many thousands of feet, as in mountainous regions. Here it is admitted that no one universal system of eolor-printing is satisfactory. This is not an unimportant matter, for it directly affects geographical education, which now is so largely assisted in schools by wall maps. In the effective preparation of these we want the opinion of both teachers and of artists.

\title{
Astronomy in the Arctic*
}

\section{Some of the Duties and Hardships of Observers in the Frigid North}

\author{
By Russell W. Porter
}

Some twenty years ago it was the fortune of the writer-or misfortune, rather-to become inoculate with the virus of that strange "wander-lust" known as the "Arctic fever." Since that time he has taken te voyages above the circle. The following notes on the part of his labors bearing on the astronomical problem arising in the extreme North may be of interest to amateur observers who have never strayed so far afield.

The duties of the astronomer of a polar expedition are the determinations of the latitude and longitude of the winter quarters, and Greenwich time. There are other activities, such as the mapping of any new lands, observations in connection with magnetic work, etc. but the-first-mentioned are the most important, particularly a knowledge of the Greenwich time-for, as we all know, the meridians of longitude converge at the Pole to a point, and the longitude is the difference between local and Greenwich time. Therefore, it is quite necessary that a person traveling toward the Pole over a shifting sea of ice should know upon what meridian he is journeying, and that on his return from the Pole $h$ should know upon which of the meridians he is descending, in order to arrive safely at his base of supplies. The compass, due to its weak horizontal component, is too unreliable a guide.

The Greenwich time is transported from civilization to the winter quarters by means of chronometers on the ship. Were their rate of gain or loss uniform, thi method would be sufficient. But the shock of the shi in forcing a passage through the ice is very great, an the clocks change their rates, so that, arriving at winter quarters after a summer's battering through icefloes, a knowledge of the time at Greenwich is very poor and not to be depended on. So recourse is had to other and absolute methods-either by occultations of stars by the moon, or moon-star culminations. From either of the moon, or moon-star culminations. From either of
these observations the center of the moon is determined in right ascension at a certain instant of local time and by entering an almanac and finding what the Greenwich time is when the moon has this right ascension, and by taking the difference between these two times the longitude is at once obtained. The degree of ac curacy so found is not great; but it must be remembere that a degree of longitude near the pole is a very much smaller quantity than at the equator, so that, for practical purposes, quite a large error is admissible.

On the writer's last Polar expedition, an observator was erected on a basalt ledge one hundred yards from the house. It was about 7 feet square, with walls of matched sheathing, north and south shutters, and a shutter in the flat and slightly inclined roof. A transit instrument by Repsold with 12-inch circles reading to instrument by Repsold with 12 -inch circles reading to
single seconds of arc was set up on a brick-pier. The single seconds of arc was set up on a brick pier. The
('hronometers at the house were never disturbed. Beat from the sidereal break-circuit clock were heard by

* From an address delivered before the First Internationa Maine. means of a sounder on the wall of the observatory. A collimating pier a few feet north of the transit served for the north meridian mark, while a signal made of several biscuit-tins, one on another, placed on a glacie a few miles away, served as a south meridian mark By swinging the instrument out of the meridian, and sighting through a hole in the wall, the magnetometer of the magnetic observatory some thousand feet away could be seen, and thus all magnetic declinations referred to the primary meridian.

The writer spent many long hours in the observatory through the winter night with his eye to the telescope watching the tiny star disks passing across the seven vertical threads of the reticule. Dressed in heavy furs, with one hand bare to record the time-intervals, he was obliged to sit motionless for sometimes two or three hours at temperatures ranging from 30 degrees to 60 degrees below zero, with no artificial heat, and the bitter wind passing freely through the building. At times the room would suddenly fill with a fog so thick as to require an immediate cessation of wark. Often the oil in the illuminating lamp hardened to the consistency of slush, and the lamp refused to burn. Tiny ice particles of hoar frost were very bothersome, settling on the pivots of the transit, and throwing the horizontal axis out of level. There was no running around the block, stamping the feet, or swinging the arms to restore circulation-just a steady, nerve-racking watch. Those observing at the magnetic hut fared no better. Here the vagaries of the needle were watched, and recorded every two minutes, over an unbroken interval of nearly two years.

The peculiar conditions surrounding the pole present other obstacles. The sun, never mounting high in the heavens, is weak in actinic rays; hence the photographer has his troubles. In using an artificial horizon with a sextant, the small angle of incidence prevents the whole disk of the sun from being observed; in fact the small transit instrument is altogether preferable to the sextant in polar work. Those made especially for the Ziegler polar expedition were but little heavie than the sextant and mercury basin, and far more useful.

During the long summer's day of four months the writer has tried to find the moon, but has never succeeded. The heavens are not blue, but a bright, glaring grey, due to the reflection of the sunlight from the surface of the snow. It very effectually "puts the moon out of business," as far as the astronomer is concerned. On the other hand, in the winter night the moon is above the horizon continually through half of each lunation, and has much the same appearance as in lower latitudes.

Imagine yourself at the pole, with the meridians of longitude radiating out from your feet until they disappear over the rim of the horizon. It is about Jun 21st, the summer solstice, and the sun is revolving around the heavens at an altitude of some 23 degrees, as ever just once in twenty-four hours, but neither risng nor descending in its path through the sky. What time is it for you as you stand there-that is, time as understood by an astronomer? The answer is easy : there is no local time. It is equally true to say that it is all hours. Now step off the pole toward the sun, whereever it may happen to be. You are now on the meridian over which the sun is situated. It is noon to youastronomical noon. Take two steps backward: you have crossed the pole, are on the same meridian, and it is astronomical midnight. In this manner you can make the time of day anything you choose by simply taking one step away from the pole in the direction of the meridian on which that particular time obtains. If you could afford to remain at this unique spot throughout a year, you would see the sun start on a slowly descending spiral until at the autumnal equinox he would be rolling around the horizon like a big billiard ball. The next day he would show only his top edge, and the next would disappear entirely for six months, slowly spiraling downward until at the winter solstice he is 23 degrees below the horizon, and begins his slow return. In March he again puts in an appearance, repeating his performance of the fall before, but in reverse order, until on June 21st he is at his highest. These would be the phenomena, provided you could see them; but the chances are that there would be but fugitive glimpses now and then, as the snow is drifting almost continually in high latitudes.

The auroral displays are, of course, of common occurrence beyond the circle, and at times in the winter become so brilliant as to lighten up the "snowscape" like full moonlight. In Franz Josef Land, north of Russia, the streamers predominate, the auroral arch not being common; but in the vicinity of the north magnetic pole the arch is seen more often. The writer has never been able to hear the peculiar sound resembling rustling silk so often spoken of by Arctic explorers as accompanying a brilliant display. And it is his impression that the great magnetic disturbances as observed in the magnetometer in winter are not necessarily accompanied by exceptionally bright auroræ.

\section{Where Timber is Wasted}

IT will surprise most people to learn that boxmakers in the United States use more than four and a half billion board feet of lumber each year, or more than one tenth of the entire lumber cut of the country. This is the authoritative statement made by the Forest Service of the Department of Agriculture, and although most of these boxes are used several times, still it is suggestive of a very considerable portion of our fast disappearing forests. Already the high price of suitable lumber is forcing manufacturers to seek other materials and more economical methods for packing and shipping their goods, 'but there is room for much greater developments in this direction. 